\section{Effect of Integrated Management of Childhood Illness (IMCl) on health worker performance in Northeast-Brazil}

\author{
O efeito da Atenção Integrada às Doenças \\ Prevalentes na Infância (AIDPI) sobre \\ o desempenho de profissionais de saúde \\ no Nordeste do Brasil
}

João Amaral 1 Eleanor Gouws 2 Jennifer Bryce 2 Álvaro Jorge Madeiro Leite 1 Antonio Ledo Alves da Cunha 3 Cesar G. Victora 4

\title{
Introduction
}

1 Departamento

de Saúde Materno Infantil, Universidade Federal

do Ceará, Fortaleza, Brasil.

2 Department of Child and Adolescent Health and Development, World Health Organization, Geneva, Switzerland.

3 Instituto de Puericultura

e Pediatria Martagão Gesteria, Universidade Federal do Rio de Janeiro, Rio de Janeiro, Brasil.

4 Departamento de Medicina Social, Universidade Federal de Pelotas, Pelotas, Brasil.

Correspondence J. Amaral

Departamento de Saúde Materno Infantil, Universidade Federal do Ceará.

Rua Prof. Costa Mendes 1608, 2o Andar, Fortaleza, CE 60430-140, Brasil.

joaoamaral@terra.com.br

\section{Abstract}

A multi-country evaluation is being carried out in Brazil and four other countries to determine the effectiveness, cost, and impact of the Integrated Management of Childhood Illness (IMCI). We examine the effect of IMCI on the quality of health care provided to children under five visiting health facilities. A health facility survey was conducted at 24 facilities (12 with IMCI) in each of four States in the Northeast. We assessed the quality of care provided to children between 2 months and 5 years attending the facilities. Health workers trained in IMCI provided significantly better care than those not trained. Significant differences between health workers who were trained or not trained in IMCI were found in the assessment of the child, disease classification, treatment, and caretaker communication. Nurses trained in IMCI performed as well as, and sometimes better than, medical officers trained in IMCI. We conclude that while there is room for further improvement, IMCI case management training significantly improves health worker performance, and that parts of Brazil that have not yet introduced IMCI should be encouraged to do so.

Health Services; Quality of Health Care; Evaluation
Despite recent advances in reducing childhood mortality in the world, over ten million children under five years of age still die every year, with the majority of these deaths occurring in developing countries 1 . Globally, almost $50 \%$ of all childhood deaths are due to pneumonia, diarrhea, measles or malaria, in combination with malnutrition $2,3,4$, all of which are preventable or treatable.

Integrated Management of Childhood Illness (IMCI) is a strategy developed by the World Health Organization (WHO), Pan-American Health Organization (PAHO), and the United Nations Children's Fund (UNICEF) with the aim of improving the health status of the world's children 5,6. The strategy includes three components: improving case-management skills of health workers, improving health systems support, and improving family and community practices. The IMCI strategy is a priority in the Brazilian Ministry of Health $(\mathrm{MoH})$ child health policies, giving special emphasis to first-level health care 7 . IMCI implementation started in Brazil in 1996 and is moving ahead strongly in several States, particularly in the Northeast and Northern regions that currently present with country's worst socioeconomic and health indicators 8 .

IMCI in Brazil is being implemented in the context of a Family Health Program (FHP), sup- 
ported by the World Bank and by the MoH. The FHP, integrated with the Community Health Worker's Program (CHWP), is included among the public policies of the $\mathrm{MoH}$ with a special emphasis on first-level care. Health care is provided to families in low-income municipalities, or neighborhoods in larger cities, by FHP teams which include a family doctor, a registered nurse, two health auxiliaries, and 4-6 community health workers (CHW). The FHP teams are based in first-level government facilities (known as Family Health Program facilities), and a given facility may have one or more teams depending on the size of its catchment area. In addition to providing comprehensive care, the FHP teams are responsible for developing activities in health promotion, prevention, early diagnosis, treatment, and rehabilitation, while patients requiring higher-level care are referred to regional centers of reference (http://www. paho.org/portuguese/gov/cd/cd41_11.pdf ).

Each FHP team covers about 600-1,000 families, and each CHW is responsible for visiting about 100-200 families at least once a month. Over 110,000 CHWs are currently operational in the country. CHW training guidelines to ensure full compatibility with IMCI have been completed (Ministry of Health. Integrated Management of Childhood Illness; 1999). The wide coverage reached by CHWs means that the community component of IMCI, which addresses key family behaviors that are essential for child health, has the potential to be implemented strongly. By January 2001, the FHP had been implemented in 1,933 municipalities with as many as 5,139 FHP teams.

FHP team members have been the primary target for IMCI case management training in Brazil. Most municipalities in which IMCI has been implemented therefore also have FHPs. However, IMCI training coverage is increasing at a much slower rate than FHP coverage, so that there are still many FHP municipalities without implementation of IMCI.

The Multi-Country Evaluation of IMCI Effectiveness, Cost and Impact (MCE), coordinated by the Department of Child and Adolescent Health and Development (CAH) of the WHO, was designed as a global evaluation to determine whether the IMCI strategy has a measurable impact on child health outcomes and to better assess its associated costs 9 . The MCE is currently under way in five countries, including Bangladesh, Brazil, Tanzania, Uganda, and Peru.

The general objective of the MCE in Brazil is to evaluate the impact of the IMCI strategy on child health by comparing municipalities with and without IMCI implementation. More specifically, the objectives include the comparison of health care provided to sick children in first-level health facilities with and without IMCI implementation, in terms of health worker performance, health systems support structure, and intensity of community activities; the comparison of health-related behaviors, intervention coverage, and impact indicators (mortality and nutrition) in municipalities with and without IMCI; the documentation of IMCI implementation at the health facility and community levels in a selected number of municipalities with strong implementation; and the assessment of costs and cost-effectiveness associated with IMCI implementation.

In this paper we report on the MCE - Brazil health facility survey conducted in 2002. The objective was to assess the effect of IMCI case management training on the quality of care provided to sick children under the age of five visiting first-level health facilities, and to compare health systems support structures in facilities in which IMCI had been implemented to those in which IMCI implementation had not yet started.

\section{Methodology}

The evaluation of IMCI in Brazil has a mixed retrospective-prospective design, because IMCI was already well implemented in many municipalities at the start of the survey. It included four steps: (1) identification of municipalities with strong IMCI implementation in four States; (2) creation of a municipal database providing baseline information on socioeconomic variables, nutrition, mortality, health services; (3) selection of comparison municipalities without IMCI implementation; and (4) conducting a Health Facility Survey (HFS).

The Ministry of Health, for inclusion in the evaluation, suggested four States, based on the fact that IMCI implementation was reported to be strong in selected municipalities. These States were Bahia, Ceará, Paraíba, and Pernambuco. Training lasted eight days in Bahia and Pernambuco, and six days in the two other States.

Only municipalities with a population between 5,000 and 50,000 were considered for inclusion in the survey in order to avoid very small municipalities in which it would be difficult to measure impact, and because the highest death rates in Brazil are in the rural municipalities with population sizes smaller than 50,000. Further criteria for both intervention and comparison municipalities included the 
presence of an adequate network of first-level health facilities (at least one facility per 10,000 inhabitants), staffing and opening hours, and an operational FHP program.

In addition, IMCI intervention municipalities were required to have a continued presence and appropriate coverage of health workers who managed children and were trained in IMCI over the previous two calendar years $(60 \%$ or more of health workers trained in IMCI), and having an $80 \%$ or higher coverage of the population with community health workers. Coverage was estimated by dividing the number of families visited monthly by CHWs in the municipality by the total number of families in that municipality. All municipalities meeting these criteria within each of the four States were included in the evaluation and matched to comparison municipalities based on geographic region and population size. Comparison municipalities were expected to have operational FHP programs but no IMCI-trained health workers. The final sample included eight IMCI and eight comparison municipalities each in the States of Paraíba and Pernambuco, seven IMCI and seven comparison municipalities in Ceará, and five IMCI and seven comparison municipalities in Bahia.

As indicated above, comparison municipalities were required to have an operational FHP but no IMCI-trained health workers. Yet, when the research team arrived in loco it became evident that this was often not the case. In several municipalities FHP was not fully implemented, and in others IMCI-trained workers from other municipalities or States had moved in. When this occurred, a new neighboring municipality was chosen, so that there were no IMCItrained workers in the comparison group. Five municipalities had to be replaced in Pernambuco, three in Bahia, and three in Ceará.

The HFS was carried out by 24 trained surveyors divided into four teams of six, one working in each of the four States between July and November of 2002. In each team, three surveyors assessed the quality of care provided to sick children and three obtained information on costs. Data on quality of care were collected through observation of case-management, exit interviews with caretakers, reexamination of each child by a trained "gold standard" surveyor, interviews with health care providers and an audit of facility supplies and equipment, using standard MCE questionnaires, adapted to the Brazilian context. Generic data-collection tools are available at http://www.who.int/imci-mce.

The performance of the health workers was assessed using standard quality of care indica- tors designed for the MCE 10, measuring performance of the health care worker in terms of several assessment tasks, correct classification (measured against the "gold standard" surveyor classification), treatment tasks, and counseling and communication tasks. In addition to individual assessment tasks, an index of integrated assessment was calculated to measure the completeness of the assessment received by sick children. The index assesses the performance of ten assessment tasks through an additive score ranging between 0 (none performed) and 1 (all tasks performed). The tasks include checking for three danger signs for severe illness (inability to drink or breastfeed, vomiting everything, convulsions), checking for diarrhea, cough, and fever, weighing the child and checking the child's weight against a growth chart, checking for palmar pallor, and checking vaccination status. This index has been found to be a valid and reliable measure of the performance of health workers after IMCI case management training 11 .

Health facility support indicators included an index to measure the availability of essential oral medications in the facility on the day of the survey (including ORS, recommended antibiotics for pneumonia, recommended antibiotics for dysentery, vitamin A, iron, mebendazole, paracetamol, and salbutamol), the availability of pre-referral injectable medications (including benzylpenicillin, gentamycin, and cloramphenicol), availability of four essential vaccines (BCG, polio, DPT, measles) and equipment to provide full vaccination services (including functioning refrigerator, sterilizer and needles/syringes), and the percentage of health facilities with all listed essential equipment (including working weighing scales for adults and children, timing device, child health cards, source of clean water, spoons, cups and jugs to mix and administer ORS). These indices ranged from zero (when none of the items were available) to one (when all of them were present).

All sick children between two months and five years of age visiting the health facility between 8AM and 5PM on the days of data collection were included in the evaluation. Each health facility was visited only once and at least one child was observed in each of these facilities. In IMCI municipalities, only sick children who were seen by an IMCI trained health worker were included.

All mothers or caretakers, according to the protocol approved by the Ethical Research Board of the School of Medicine at the Federal University in Ceará, gave informed consent for participation in the study. 


\section{Data management}

The central team for data processing included two data clerks and one research assistant. Data were double-entered using two independent data entry clerks, and discrepancies between the two versions were resolved with reference to the original data forms. Standard range and consistency checks were carried out.

The standard MCE analytical plan was adapted for data analysis 10. Statistical analysis was carried out using STATA version 7 for Windows.

Comparisons of performance between health workers who received training in IMCI and those who have not yet received training in IMCI were adjusted for differences in the percentage of IMCI trained medical officers and nurses in the four States using Poisson regression with robust variance estimators. Chi-square or Fisher's exact tests were used for comparisons stratified by States and for comparisons between IMCI trained doctors and nurses. Clustering of children at the health facility level was accounted for in the statistical analysis of the case management indicators. Statistical significance was set at $\mathrm{p}<0.05$.

Indicators to measure health facility support were compared between facilities in which IMCI had been implemented (IMCI facilities) and facilities in which IMCI had not yet been implemented (non-IMCI facilities) using chisquare for comparison of percentages or t-test or analysis of variance for comparison of means.

\section{Results}

From each of the four States, including $12 \mathrm{mu}$ nicipalities in Bahia, 14 municipalities in Ceará, 16 municipalities in Paraíba, and 16 municipalities in Pernambuco, a total of 24 health facilities (12 with and 12 without IMCI) were selected for inclusion in the survey. In total, 653 children were sampled from these 96 facilities. An average of about 4 children were observed per facility in Bahia (range 1-8), 8 per facility in Ceará (range 3-10), 8 per facility in Paraíba (range 6-10), and 7 per facility in Pernambuco (range 7-10). The number of children observed in Bahia was smaller than in the other three States because access to facilities is more difficult in this State and fewer well-baby visits were being made.

Medical officers saw the majority of the 653 children included in the survey, $87 \%$, while registered nurses saw the remaining $13 \%$. When data from all facilities were analyzed jointly, $39 \%$ of the medical officers (doctors) who treat- ed children included in the survey had received training in IMCI, while $83.9 \%$ of the nurses had been trained in IMCI. Table 1 shows the number of children seen by IMCI trained and nonIMCI trained medical officers and nurses in each of the four States included in the survey.

Among the 653 children included in the survey, $27 \%$ were between the ages of 2 to 11 months, $29 \%$ between 12 and 23 months, and $44 \%$ were between 2 years and 5 years old. Fifty-two percent of all sick children were boys.

The distribution of presenting illnesses among children whose case management was observed, based on the "gold standard" surveyor classification, is presented in Figure 1. Differences in profiles between those children seen by IMCI trained health workers and nonIMCI trained health workers were not statistically significant. Of all children, the majority (52\%) presented at the facility with a cough or cold. Twenty-eight percent had a fever, $15 \%$ had diarrhea with no dehydration, $81 \%$ presented with anemia, and $9 \%$ with wheezing. Ten percent of all children sampled at the facilities had asthma, while $46 \%$ had other illnesses currently not included in IMCI guidelines, the most frequent diagnosis of which included skin or throat problems. A large percentage of children (58\%) who were included in this survey presented at the facilities with more than one illness. Among children who had other, non-IMCI related, illnesses, $78 \%$ had these illnesses in combination with an IMCI-related illness, while $22 \%$ only had this other illness.

\section{Health worker performance}

Health worker performance was evaluated in terms of assessment tasks, correct classification of illness, treatment of the sick child, and communication with the caretaker, using standard MCE indicators.

Comparison in performance between health workers trained in IMCI and those not trained in IMCI, with adjustment for potential confounders (type of health worker and State) and adjustment for the survey design, are presented in Table 2.

In terms of assessment tasks, Table 2 shows that health workers who had received training in IMCI performed significantly better than those who had not received training in IMCI in all but two tasks. Too few children ( 8 in total) presented with very low weight to produce a statistically significant result.

Health workers who had received training in IMCI were significantly more likely to classify a child correctly than those who had not re- 
ceived training in IMCI, with an adjusted prevalence ratio of 2 (95\% CI: 1.6-2.4; $\mathrm{p}<0.001)$.

Health workers who had received training in IMCI performed significantly better than those who had not received training in IMCI in only one of five treatment indicators. Significantly more sick children $(27 \%)$ received the first dose of medication at the facility if they had been seen by an IMCI trained health worker as compared to a non-IMCI trained health worker $(0 \%)$. Although more children with pneumonia who were seen by an IMCI trained health worker received correct treatment (58\%) than those seen by a non-IMCI trained health worker (29\%), the difference was not statistically significant, possibly because of the small number of children who presented with pneumonia.

Communication with the caretaker improved significantly if the health worker had received training in IMCI. Significantly more caretakers were advised to give extra fluid to a sick child, advised on how to give oral medication, and advised on when to return to the facility immediately if seen by a health worker trained in IMCI compared to a non-IMCI trained health worker (Table 2). However, knowledge in relation to administration of oral medication was significantly higher among caretakers of children seen by non-IMCI trained health workers than among those seen by IMCI trained health workers.

In Table 3 the performance of IMCI trained medical officers was compared to non-IMCI trained medical officers within each of the four States. Analysis was restricted to medical officers because of the small number of nurses in Paraíba and Pernambuco (eight nurses in $\mathrm{Pa}-$ raíba, none of whom had been trained in IMCI, and no nurses in Pernambuco). The analysis showed that IMCI training generally improved performance of medical officers in each of the States, with significant improvement on most of the assessment tasks. IMCI trained medical officers were significantly more likely to classify a child correctly in all States, with the excep-

Table 1

Number of sick children between the ages of two months and five years included in the MCE health facility survey in four States in Northeast Brazil who were observed being managed by $1 \mathrm{MCl}$ trained and non-IMCl trained medical officers and nurses.

\begin{tabular}{lrrrrr}
\hline & Bahia & Ceará & Paraíba & Pernambuco & Total \\
\hline IMCl trained & 25 & 49 & 64 & 84 & 222 \\
$\quad$ Medical officers & 29 & 44 & 0 & 0 & 73 \\
Nurses & 54 & 93 & 64 & 84 & 295 \\
Total & & & & & \\
Non-IMCl trained & 46 & 99 & 112 & 87 & 344 \\
Medical officers & 5 & 1 & 8 & 0 & 14 \\
Nurses & 51 & 100 & 120 & 87 & 358 \\
$\quad$ Total & 105 & 193 & 184 & 171 & 653 \\
Total & & & & & \\
\hline
\end{tabular}

$\mathrm{IMCl}=$ Integrated Management of Childhood IIIness.

Figure 1

Distribution of illnesses of children seen by $\mathrm{IMCl}$ trained and non-trained health workers in Northeast Brazil.

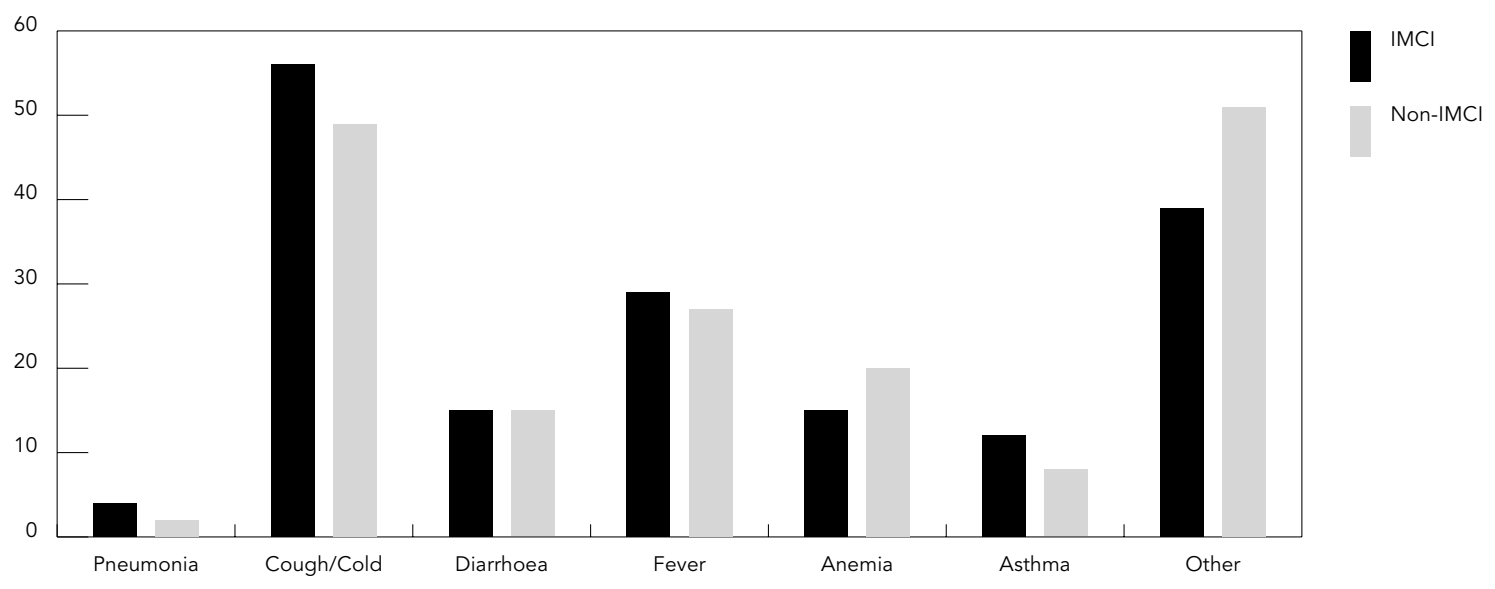

$\mathrm{IMCl}=$ Integrated Management of Childhood IIIness 
Differences in health worker performance between $\mathrm{IMCl}$ trained and non-trained health workers.

Prevalence ratios and $p$-values were adjusted for differences between the four States and between doctors and nurses.

Clustering at the health facility level was accounted for in the analysis.

\begin{tabular}{|c|c|c|c|c|c|c|}
\hline \multirow[t]{2}{*}{ Indicator } & \multicolumn{2}{|c|}{$\begin{array}{l}\mathrm{IMCl} \text { trained } \\
\text { health workers }\end{array}$} & \multicolumn{2}{|c|}{$\begin{array}{l}\text { Non-IMCl trained } \\
\text { health workers }\end{array}$} & \multirow[t]{2}{*}{$\begin{array}{l}\text { Adjusted prevalence } \\
\text { ratio }(95 \% \mathrm{Cl})\end{array}$} & \multirow[t]{2}{*}{ p-value } \\
\hline & $\mathrm{n}$ & $\%$ & $\mathrm{n}$ & $\%$ & & \\
\hline \multicolumn{7}{|l|}{ Assessment tasks } \\
\hline Child checked for 3 danger signs & 295 & 38.3 & 358 & 0.6 & $64.5(15.1-275.0)$ & $<0.0001$ \\
\hline Checked for cough, diarrhea, fever & 295 & 75.9 & 358 & 32.9 & $2.32(1.85-2.89)$ & $<0.0001$ \\
\hline Weight checked against growth chart & 295 & 77.3 & 358 & 36.3 & $1.86(1.44-2.43)$ & $<0.0001$ \\
\hline Vaccination status checked & 294 & 68.4 & 357 & 43.9 & $1.33(1.06-1.66)$ & 0.013 \\
\hline Child $<2 y$ assessed for feeding practices & 158 & 35.4 & 168 & 10.1 & $3.00(1.79-5.02)$ & $<0.0001$ \\
\hline Child checked for other problems & 89 & 68.5 & 124 & 76.6 & $0.97(0.85-1.11)$ & 0.649 \\
\hline Child with low weight checked for feeding problems & 4 & 25.0 & 4 & 0.0 & $\mathrm{n}$ too small & 0.347 \\
\hline Index of integrated assessment & 294 & 0.72 & 357 & 0.421 & - & $<0.0001$ \\
\hline \multicolumn{7}{|l|}{ Classification } \\
\hline Child classified correctly & 294 & 65.3 & 358 & 31.3 & $1.96(1.58-2.43)$ & $<0.0001$ \\
\hline \multicolumn{7}{|l|}{ Treatment tasks } \\
\hline Child needing antibiotics prescribed correctly & 33 & 66.7 & 35 & 51.4 & $1.14(0.73-1.77)$ & 0.567 \\
\hline Child not needing antibiotics leaves without antibiotics & 261 & 92.7 & 323 & 86.7 & $1.02(0.95-1.09)$ & 0.515 \\
\hline Child needing vaccines leaves with all & 96 & 38.5 & 105 & 38.1 & $0.73(0.42-1.26)$ & 0.263 \\
\hline Child with pneumonia treated correctly & 12 & 58.3 & 7 & 28.6 & $2.04(0.48-8.67)^{2}$ & 0.333 \\
\hline Child received first dose of medication at facility & 33 & 27.3 & 35 & 0.0 & - & $<0.001$ \\
\hline \multicolumn{7}{|l|}{ Communication } \\
\hline Caretaker advised to give extra fluid & 291 & 54.6 & 357 & 33.3 & $1.49(1.2-1.85)$ & $<0.001$ \\
\hline Caretaker with ORS or antibiotics knows how to give it & 70 & 65.7 & 106 & 77.4 & $0.78(0.61-0.97)$ & 0.028 \\
\hline Advice given to caretaker on oral medication & 68 & 57.4 & 102 & 24.5 & $2.1(1.3-3.4)$ & 0.002 \\
\hline Caretaker advised on when to return immediately & 294 & 42.2 & 358 & 1.4 & $29.46(7.71-112.6)$ & $<0.0001$ \\
\hline
\end{tabular}

1 Indicates that mean value was reported.

2 Unadjusted prevalence ratio because of small $n$.

$\mathrm{IMCl}=$ Integrated Management of Childhood IIIness.

tion of Ceará where the difference in correct classification between trained and untrained doctors was not significant. Treatment tasks among medical officers generally did not show significant improvement with IMCI training, but communication with the caretaker improved significantly in at least two tasks in $\mathrm{Pa}$ raiba and Pernambuco if the medical officer received training in IMCI.

Table 3 shows large variation in the quality of care among IMCI trained medical officers from one State to another. Health workers in Pernambuco performed significantly better in most tasks than health workers in other States. Poor performance was generally observed in Bahia, even among IMCI-trained medical officers.

In Table 4 the performance of IMCI trained medical officers and nurses were compared in the two States in which both nurses and med- ical officers were observed (Bahia and Ceará). The results show that differences between medical officers and nurses were generally not significant. Nurses were significantly better than doctors in the correct classification of illness in Bahia and they were significantly more likely than doctors to advise caretakers to give extra fluid to a sick child in Ceará.

\section{Health systems support}

Within the 48 facilities in which at least one health worker had been trained in IMCI case management, $65 \%$ reported that at least $60 \%$ of all workers managing children had been trained in IMCI. This percentage varied between the 4 States, from $50 \%$ in Bahia and Ceará, to $58.3 \%$ in Paraíba and $100 \%$ in Pernambuco ( $\mathrm{p}=0.029)$. 
Comparison of performance between $\mathrm{IMCl}$ and non- $\mathrm{IMCl}$ trained medical officers by state.

\begin{tabular}{|c|c|c|c|c|c|c|c|c|}
\hline \multirow[t]{2}{*}{ Indicator } & \multicolumn{2}{|c|}{ Bahia } & \multicolumn{2}{|c|}{ Ceará } & \multicolumn{2}{|c|}{ Paraíba } & \multicolumn{2}{|c|}{ Pernambuco } \\
\hline & $\begin{array}{c}\mathrm{IMCl} \\
\text { trained } \\
(\mathrm{n}=25)\end{array}$ & $\begin{array}{l}\text { Non- } \mathrm{IMCl} \\
(\mathrm{n}=46)\end{array}$ & $\begin{array}{l}\mathrm{IMCl} \\
(\mathrm{n}=49)\end{array}$ & $\begin{array}{l}\text { Non-IMCI } \\
(\mathrm{n}=99)\end{array}$ & $\begin{array}{c}\mathrm{IMCl} \\
(\mathrm{n}=64)\end{array}$ & $\begin{array}{l}\text { Non-IMCl } \\
(n=112)\end{array}$ & $\begin{array}{c}\mathrm{IMCl} \\
(\mathrm{n}=84)\end{array}$ & $\begin{array}{c}\text { Non-IMCI } \\
(n=87)\end{array}$ \\
\hline \multicolumn{9}{|l|}{ Assessment tasks } \\
\hline Child checked for 3 danger signs (\%) & 8.01 & 0.0 & 22.51 & 0.0 & 29.73 & 0.89 & 76.23 & 0.0 \\
\hline Checked for cough, diarrhea, fever (\%) & 64.03 & 17.4 & 59.21 & 21.2 & 78.11 & 45.5 & 97.63 & 36.8 \\
\hline Weight checked against growth chart (\%) & 24.0 & 6.5 & 71.43 & 13.1 & 82.83 & 13.4 & 98.8 & 100.0 \\
\hline Vaccination status checked (\%) & 33.3 & 15.2 & 51.0 & 23.2 & 56.31 & 24.3 & 100.0 & 28.6 \\
\hline Child $<2 y$ assessed - feeding practices (\%) & 8.3 & 0.0 & 10.0 & 2.1 & 30.31 & 10.9 & 74.52 & 28.6 \\
\hline Child checked for other problems (\%) & $\begin{array}{c}12.5 \\
(n=8)\end{array}$ & $\begin{array}{c}14.2 \\
(n=21)\end{array}$ & $\begin{array}{l}35.71 \\
(n=14)\end{array}$ & $\begin{array}{c}66.7 \\
(n=21)\end{array}$ & $\begin{array}{c}100.0 \\
(n=40)\end{array}$ & $\begin{array}{c}95.1 \\
(n=61)\end{array}$ & $\begin{array}{l}100.0 \\
(n=8)\end{array}$ & $\begin{array}{l}100.0 \\
(n=15)\end{array}$ \\
\hline Index of integrated assessment (mean) & 0.563 & 0.31 & 0.613 & 0.26 & 0.723 & 0.43 & 0.933 & 0.61 \\
\hline \multicolumn{9}{|l|}{ Classification } \\
\hline Child correctly classified (\%) & 44.01 & 19.6 & 45.8 & 43.4 & 48.42 & 23.2 & 95.23 & 35.6 \\
\hline \multicolumn{9}{|l|}{ Treatment tasks } \\
\hline Child needing antibiotics prescribed correctly & $\begin{array}{l}40.0 \\
(n=5)\end{array}$ & $\begin{array}{l}50.0 \\
(n=8)\end{array}$ & $\begin{array}{l}100.0 \\
(n=2)\end{array}$ & $\begin{array}{c}42.9 \\
(n=7)\end{array}$ & $\begin{array}{c}53.3 \\
(n=15)\end{array}$ & $\begin{array}{c}43.7 \\
(n=16)\end{array}$ & $\begin{array}{l}100.0 \\
(n=5)\end{array}$ & $\begin{array}{l}100.0 \\
(n=3)\end{array}$ \\
\hline $\begin{array}{l}\text { Child not needing antibiotics leaves } \\
\text { without antibiotics }(\%)\end{array}$ & 100.0 & 78.9 & 84.8 & 86.9 & 83.7 & 76.0 & 97.0 & 100.0 \\
\hline Child needing vaccines leaves with all (\%) & $\begin{array}{c}57.1 \\
(n=14)\end{array}$ & $\begin{array}{l}50.0 \\
(n=6)\end{array}$ & $\begin{array}{c}33.3 \\
(n=12)\end{array}$ & $\begin{array}{c}24.4 \\
(n=41)\end{array}$ & $\begin{array}{c}10.0 \\
(n=20)\end{array}$ & $\begin{array}{c}23.3 \\
(n=30)\end{array}$ & $\begin{array}{c}332 \\
(n=27)\end{array}$ & $\begin{array}{c}86.9 \\
(n=23)\end{array}$ \\
\hline \multicolumn{9}{|l|}{ Communication } \\
\hline Caretaker advised to give extra fluid (\%) & 20.0 & 6.5 & 14.9 & 18.4 & 57.82 & 21.4 & 96.42 & 75.8 \\
\hline $\begin{array}{l}\text { Caretaker with ORS or antibiotics knows } \\
\text { how to give it (\%) }\end{array}$ & $\begin{array}{l}80.0 \\
(n=5)\end{array}$ & $\begin{array}{c}61.5 \\
(n=13)\end{array}$ & $\begin{array}{c}50.0 \\
(n=16)\end{array}$ & $\begin{array}{c}84.8 \\
(n=33)\end{array}$ & $\begin{array}{c}61.5 \\
(n=13)\end{array}$ & $\begin{array}{c}72.2 \\
(n=36)\end{array}$ & $\begin{array}{c}60.0 \\
(n=20)\end{array}$ & $\begin{array}{c}81.8 \\
(n=22)\end{array}$ \\
\hline Advice to caretaker on medication (\%) & $\begin{array}{c}10.0 \\
(n=10)\end{array}$ & $\begin{array}{c}11.1 \\
(n=18)\end{array}$ & $\begin{array}{c}40.0 \\
(n=5)\end{array}$ & $\begin{array}{c}11.1 \\
(n=18)\end{array}$ & $\begin{array}{c}48.22 \\
(n=27)\end{array}$ & $\begin{array}{c}9.8 \\
(n=41)\end{array}$ & $\begin{array}{c}100.0 \\
(n=16)\end{array}$ & $\begin{array}{c}70.8 \\
(n=24)\end{array}$ \\
\hline Caretaker advised when to return immediately (\%) & 16.0 & 6.5 & 16.72 & 1.0 & 29.72 & 0.0 & 100.03 & 0.0 \\
\hline
\end{tabular}

$\mathrm{IMCl}=$ Integrated Management of Childhood IIIness.

$1 p<0.05$

$2 p<0.01$;

$3 p \leq 0.001$

Supervision in the facilities included in this survey was generally poor. Among all facilities in which health workers had received training in IMCI, only 19\% (9/48) had received at least one supervisory visit that included observation of case management during the previous six months. This figure differed significantly between the four States: $25 \%$ of facilities in Bahia, 0\% in Ceará, $8 \%$ in Paraíba, and $42 \%$ in Pernambuco had received at least one supervisory visit that included observation of case management $(\mathrm{p}=0.045)$.

Table 5 shows that health facilities that were included in this survey had a good supply of essential oral drugs (a score of 1.0 was given to facilities with all essential drugs), with the index being significantly higher in facilities in which IMCI had been introduced compared to facilities in which IMCI had not yet been intro- duced. The index of availability of four essential vaccines was high in both IMCI as well as non-IMCI facilities. Almost all facilities had all essential equipment and supplies to support full vaccination services. Availability of pre-referral injectable drugs was generally low in both IMCI and non-IMCI facilities. The availability of all essential equipment and material was also generally low, but significantly higher $(56 \%)$ in facilities with IMCI than in facilities with no IMCI (28\%) (Table 5).

Variation in health system support indicators between the four States included in this survey, for facilities with and without IMCI, is shown in Table 6. Pernambuco had consistently higher levels of facility support than the other three States. 
Performance of health care workers trained in $\mathrm{IMCl}$, stratified by State and type of health worker.

Comparisons are between medical officers and nurses in each State.

\begin{tabular}{|c|c|c|c|c|c|c|c|c|}
\hline \multirow[t]{2}{*}{ Indicator } & \multicolumn{2}{|c|}{ Bahia } & \multicolumn{2}{|c|}{ Ceará } & \multicolumn{2}{|c|}{ Paraíba } & \multicolumn{2}{|c|}{ Pernambuco } \\
\hline & $\begin{array}{l}\text { Medical } \\
\text { officers } \\
(n=25)\end{array}$ & $\begin{array}{l}\text { Nurses } \\
(n=29)\end{array}$ & $\begin{array}{l}\text { Medical } \\
\text { officers } \\
(n=49)\end{array}$ & $\begin{array}{l}\text { Nurses } \\
(n=44)\end{array}$ & $\begin{array}{l}\text { Medical } \\
\text { officers } \\
(n=64)\end{array}$ & $\begin{array}{l}\text { Nurses } \\
(n=0)\end{array}$ & $\begin{array}{c}\text { Medical } \\
\text { officers } \\
(n=84)\end{array}$ & $\begin{array}{l}\text { Nurses } \\
(n=0)\end{array}$ \\
\hline \multicolumn{9}{|l|}{ Assessment tasks } \\
\hline Child checked for 3 danger signs (\%) & 8.0 & 20.7 & 22.5 & 25.0 & 29.7 & - & 76.2 & - \\
\hline Checked for cough, diarrhea, fever (\%) & 64.0 & 79.3 & 59.2 & 54.6 & 78.1 & & 97.6 & \\
\hline Weight checked against growth chart (\%) & 24.0 & 55.2 & 71.4 & 79.6 & 82.8 & & 98.8 & \\
\hline Vaccination status checked (\%) & 33.3 & 44.8 & 51.0 & 79.6 & 56.3 & & 100.0 & \\
\hline Child $<2 y$ assessed - feeding practices (\%) & 8.3 & 6.7 & 10.0 & 14.8 & 30.3 & & 74.5 & \\
\hline Child checked for other problems (\%) & $\begin{array}{c}12.5 \\
(n=8)\end{array}$ & $\begin{array}{c}44.4 \\
(n=9)\end{array}$ & $\begin{array}{c}35.7 \\
(n=14)\end{array}$ & $\begin{array}{c}30.0 \\
(n=10)\end{array}$ & $\begin{array}{c}100.0 \\
(n=40)\end{array}$ & & $\begin{array}{l}100.0 \\
(n=8)\end{array}$ & \\
\hline Index of integrated assessment (mean) & 0.56 & 0.61 & 0.61 & 0.62 & 0.72 & & 0.93 & \\
\hline \multicolumn{9}{|l|}{ Classification } \\
\hline Child correctly classified (\%) & 44.01 & 82.8 & 45.8 & 54.6 & 48.4 & - & 95.2 & - \\
\hline \multicolumn{9}{|l|}{ Treatment tasks } \\
\hline Child needing antibiotics prescribed correctly & $\begin{array}{c}40.0 \\
(n=5)\end{array}$ & $\begin{array}{l}100.0 \\
(n=3)\end{array}$ & $\begin{array}{l}100.0 \\
(n=2)\end{array}$ & $\begin{array}{c}66.7 \\
(n=3)\end{array}$ & $\begin{array}{c}53.3 \\
(n=15)\end{array}$ & - & $\begin{array}{l}100.0 \\
(n=5)\end{array}$ & - \\
\hline $\begin{array}{l}\text { Child not needing antibiotics leaves } \\
\text { without antibiotics (\%) }\end{array}$ & 100 & 96.2 & 84.8 & 97.6 & 83.7 & & 97.0 & \\
\hline Child needing vaccines leaves with all (\%) & 57.1 & 50.0 & 33.3 & 66.7 & 10.0 & & 33.0 & \\
\hline \multicolumn{9}{|l|}{ Communication } \\
\hline Caretaker advised to give extra fluid (\%) & 20.0 & 22.2 & 14.93 & 52.3 & 57.8 & - & 96.4 & - \\
\hline $\begin{array}{l}\text { Caretaker with ORS or antibiotics knows } \\
\text { how to give it (\%) }\end{array}$ & 80.0 & 87.5 & 50.0 & 87.5 & 61.5 & & 60.0 & \\
\hline Advice to caretaker on medication (\%) & $\begin{array}{c}10.0 \\
(n=10)\end{array}$ & $\begin{array}{c}60.0 \\
(n=5)\end{array}$ & $\begin{array}{c}40.0 \\
(n=5)\end{array}$ & $\begin{array}{c}80.0 \\
(n=5)\end{array}$ & $\begin{array}{c}48.2 \\
(n=27)\end{array}$ & & $\begin{array}{c}100.0 \\
(n=16)\end{array}$ & \\
\hline Caretaker advised when to return immediately (\%) & 16.0 & 17.2 & 16.72 & 9.1 & 29.7 & & 100.0 & \\
\hline
\end{tabular}

$\mathrm{IMCl}=$ Integrated Management of Childhood IIIness.

$1 \mathrm{p}<0.05$;

$2 \mathrm{p}<0.01$

$3 p \leq 0.001$.

\section{Discussion}

The results from this study show that the quality of care provided to sick children attending firstlevel health facilities in four States in Northeast Brazil was significantly improved if the health care professional received training in IMCI compared to health care workers who had not received training in IMCI. Significant differences between IMCI trained and non-IMCI trained health workers were observed in the assessment of the sick child, classification of illness, and treatment of the child, as well as in communication with the caregiver of the sick child. These results are consistent with findings described in other MCE sites, Tanzania 12 and Uganda 13.

Although the majority of indicators show that quality of care improved significantly with training in IMCI, levels of performance for some indicators, such as checking for at least three danger signs and evaluation of feeding practices, were still low, even after IMCI training, leaving room for further improvement. These findings are worrisome because a delay in the identification of seriously sick children may affect the probability of survival. Experienced doctors and nurses may argue that there is no need to ask for danger signs explicitly, but except for lethargy, the other three signs that should be investigated (history of convulsions, inability to eat or drink, or vomiting everything) require proactive questioning of the mother.

Quality of treatment for pneumonia, as well as the administration of necessary vaccines and providing the first dose of medication at the facility were low, even after training in IMCI, and 
Health system support indicators for facilities in which $\mathrm{IMCl}$ had been introduced compared to facilities in which $\mathrm{IMCl}$ had not yet been introduced.

\begin{tabular}{|c|c|c|c|}
\hline Health systems support indicator & $\begin{array}{l}\text { Facilities with IMCI } \\
\qquad \mathrm{n}=48\end{array}$ & $\begin{array}{l}\text { Non-IMCI facilities } \\
\qquad n=48\end{array}$ & p-value \\
\hline Drugs/vaccines & Mean (SD) & Mean (SD) & \\
\hline Index of availability of essential oral treatment & $0.82(0.017)$ & $0.77(0.015)$ & 0.0478 \\
\hline Index of availability of injectable drugs & $0.39(0.037)$ & $0.44(0.031)$ & 0.298 \\
\hline Index of availability of four vaccines & $0.90(0.033)$ & $0.85(0.041)$ & 0.331 \\
\hline Equipment & Percentage & Percentage & \\
\hline $\begin{array}{l}\text { Facility has all equipment and supplies } \\
\text { to support full vaccination services }\end{array}$ & 100.0 & 93.6 & 0.075 \\
\hline Health facility has all essential equipment and materials & 56.3 & 27.7 & 0.005 \\
\hline
\end{tabular}

$\mathrm{IMCl}=$ Integrated Management of Childhood IIIness

Comparison between the facilities in the four States $(\mathrm{IMCl}$ and non- $\mathrm{IMCl})$ with relation to health systems support indicators.

\begin{tabular}{|c|c|c|c|c|c|c|c|c|}
\hline \multirow[t]{2}{*}{ Indicator } & \multicolumn{2}{|c|}{ Bahia } & \multicolumn{2}{|c|}{ Ceará } & \multicolumn{2}{|c|}{ Paraíba } & \multicolumn{2}{|c|}{ Pernambuco } \\
\hline & $\mathrm{IMCl}$ & Non & $\mathrm{IMCl}$ & Non & $\mathrm{IMCl}$ & Non & $\mathrm{IMCl}$ & Non \\
\hline \multicolumn{9}{|l|}{ Drugs/vaccines (means) } \\
\hline Index of availability of essential oral treatment & 0.84 & 0.76 & 0.76 & 0.73 & 0.75 & 0.73 & 0.91 & 0.85 \\
\hline Index of availability of injectable drugs & 0.33 & 0.33 & 0.31 & 0.50 & 0.28 & 0.36 & 0.63 & 0.56 \\
\hline Index of availability of four vaccines & 0.81 & 0.64 & 0.96 & 0.92 & 0.83 & 0.83 & 1.00 & 1.00 \\
\hline \multicolumn{9}{|l|}{ Equipment (percentage) } \\
\hline $\begin{array}{l}\text { Facility has all equipment and supplies } \\
\text { to support full vaccination services }\end{array}$ & 100.0 & 91.0 & 100.0 & 100.0 & 100.0 & 83.3 & 100.0 & 100.0 \\
\hline $\begin{array}{l}\text { Health facility has all essential equipment } \\
\text { and materials }\end{array}$ & 41.7 & 0.0 & 50.0 & 41.7 & 58.0 & 16.7 & 75.0 & 50.0 \\
\hline
\end{tabular}

$\mathrm{IMCl}=$ Integrated Management of Childhood IIIness.

could negatively impact prevention of illness or improvement of the sick child.

Indicators measuring aspects of communication between the health worker and the caregiver or family of the sick child revealed better performance among health workers who received training in IMCI, except for the indicator measuring the knowledge of the caregiver on how to give ORS or antibiotics to the child. This indicator showed a reasonably high level of knowledge of the caregiver, whether the child was seen by an IMCI trained or non-IMCI trained health worker. This could be explained by the increase in the emphasis on the control of diarrhea over the last years in Brazil. Many programs on the treatment of diarrhea, and reinforcing the use of ORS in the home, have led to a decline in diarrhea cases as well as better knowledge on how to use ORS 14. Among the mothers who were given ORS in this study, 93\% knew how to give it.

Comparisons of quality of care indicators among medical officers in each of the four States included in this survey showed substantial variation in performance of the health workers in the different States. Indicators in Pernambuco (among IMCI as well as non-IMCI trained medical officers) were consistently higher than in the other three States and could be explained by the higher level of supervision and facility support, and the more systematic way in which health care activities have been carried out. Extensive guidelines and manuals for the implementation of IMCI have been de- 
veloped in Pernambuco. The positive association between performance of health workers and continued supervision activities is consistent with findings in other sites 13 . Poor performance in Bahia could be attributed to the low IMCI coverage and the fact that, among the States included in the survey, Bahia was the last to have started with IMCI training.

No clear patterns were observed when comparing performance between IMCI trained medical officers and nurses in Bahia and Ceará. The results show that nurses perform as well as, and in some instances better than, medical officers trained in IMCI. This result is particularly important in view of the fact that medical associations in Brazil successfully managed to stop the $\mathrm{MoH}$ from training nurses in IMCI in 2001, arguing that the latter are not allowed to prescribe any drugs under the current legislation.

The illnesses with which children presented to health facilities within this survey reflect the most common illnesses among children under five in Northeast Brazil. No difference was observed in the illnesses of children attended to by health workers trained in IMCI and health workers not trained in IMCI. A large percentage (46\%) of children presented at the facilities with illnesses not currently included in the IMCI guidelines, although in $78 \%$ of these cases, the child also presented with an IMCIrelated illness. However, this stresses the importance of IMCI guidelines being adapted to include illnesses specific to a particular country or region.

The study showed good availability of essential oral medication, vaccines, and equipment and supplies to deliver vaccines. However, even though a high level of availability was observed for vaccines, this should be increased to $100 \%$ availability because vaccines are pro-

\section{Resumo}

Uma avaliação está sendo realizada entre cinco países, inclusive o Brasil, para determinar a efetividade, custo e impacto da Atenção Integrada às Doenças Prevalentes na Infância (AIDPI). Os autores examinam o efeito da AIDPI sobre a qualidade da assistência prestada a crianças abaixo de cinco anos em consultas realizadas em serviços de saúde. Foi feito um inquérito em 24 serviços de saúde (12 com AIDPI) em cada um de quatro estados do nordeste. Avaliou-se a qualidade da assistência prestada às crianças entre 2 meses $e 5$ anos de idade que freqüentavam os serviços. Profissionais de saúde treinados em AIDPI prestavam assistência significativamente melhor, comparada com aqueles sem treinamento em AIDPI. Foram observadas diferenças significativas entre profissionais com vided free of charge by the government of Brazil. It is therefore also important to increase the provision of vaccines. Availability of pre-referral injectable drugs and medical supplies was generally low. This could be problematic because the absence of such medication in primary health centers would lead to the transfer of a seriously ill child without receiving the necessary first dose of medication.

A limitation of the study is the high turnover of professional staff. In 2001, municipalities were selected for inclusion in the IMCI intervention arm of this study on the basis of having more than $60 \%$ of staff trained in IMCI. However, when the study was conducted in 2002, only $65 \%$ of the 48 facilities reported having more than $60 \%$ of staff trained in IMCI. Professional staff turnover, a common phenomenon in many developing countries 15 , could be explained by higher salaries being offered to trained staff by other municipalities as well as increased opportunities to continue graduate education or improved career opportunities. A further limitation of the study is that the samples of professionals included in each State was not deemed to be representative of the whole State because the primary objective was to compare IMCI trained versus other health workers in small to medium-sized municipalities.

The findings in this study show that while there is room for further improvement, training in IMCI significantly improves health worker performance in Northeast Brazil. States in other parts of Brazil that have not yet introduced IMCI in first-level facilities should be encouraged to do so. Further research is needed to assess the effect of improving health worker performance in the causal chain of assessing the impact of the IMCI strategy in reducing childhood mortality. e sem treinamento em AIDPI, na avaliação da criança, classificação da doença, tratamento e comunicação com os pais ou cuidadores. Enfermeiros treinados em AIDPI mostravam desempenho tão bom quanto, e às vezes melhor do que médicos treinados em AIDPI. Os autores concluem que, embora ainda exista espaço para melhoria, o treinamento em AIDPI melhora o desempenho dos profissionais de saúde no tratamento de crianças, e que as regiões brasileiras que ainda não implementaram a AIDPI devem ser incentivadas com o intuito de adotá-lo.

Serviços de Saúde; Qualidade dos Cuidados de Saúde; Avaliação 


\section{Contributors}

J. Amaral contributed to the planning, supervision, and analysis. E. Gouws collaborated in the statistical analysis. J. Bryce and C. G. Victora contributed to the planning and analysis. A. J. M. Leite and A. L. A. Cunha participated in the analysis.

\section{Acknowledgements}

The authors wish to express their sincere gratitude for contributions and support from: Health Facility Survey interviewers: Gilda M. Bringel, Rosiani P. Videres Alexandre F. C. Oliveira, Antonia Elísia P. Santos, Ionise B. S. França, Joacilda da C. Nunes, Tânia Ribeiro, Verônica S. Castro, Mary E. M. Silveira, Benedita R. Soares, Débora G. Amorim, Diva de L. a Fernandes, Daisy Silva, Luzia M. V. Machado, Heliane B. S. Farias, Regina Célia L. C. Silva, Maria Rosário R. Barretto, Maria Ester S. Marinho, Cristina C. dos Santos, Maria das Graças de Sá Magalhães, Maria Leopoldina P. Falcão, Luciana G. F. Ferreira, Maria Madalena M. R. de Oliveira, Maria Fernanda de C. Barbosa, Gláucia M. P. Espindola; Ministry of Health, Brazil: Maria Anice Fontenele S Silva, Ana Goretti Maranhão, Danuza Benjamin, Celina S Kawano; Pan-American Health Organization: Julio Javier Espindola, Christopher Drasbeck, Yehuda Benguigu

\section{References}

1. Ahmad OB, Lopez AD, Inoue M. The decline in child mortality: a reappraisal. Bull World Health Organ 2000; 78:1175-91.

2. Black RE, Morris SS, Bryce J. Where and why are 10 million children dying every year? Lancet 2003; 361:2226-34.

3. Integrated management of the sick child. Bull World Health Organ 1995; 73:735-40.

4. World Health Organization. World Health Report: making a difference. Geneva: World Health Organization; 1999

5. Gove S. Integrated Management of Childhood Illness by outpatient health workers: technical basis and overview. The WHO Working Group on Guidelines for Integrated Management of the Sick Child. Bull World Health Organ 1997; 75 Suppl 1:7-24.

6. Integrated Management of Childhood Illness: conclusions. WHO Division of Child Health and Development. Bull World Health Organ 1997; 75 Suppl 1:119-28.

7. Cunha ALA, Silva MAF, Amaral J. A estratégia de "Atenção Integrada às Doenças Prevalentes na Infância - AIDPI" e sua implantação no Brasil. Rev Pediatr Ceará 2001; 2:33-8.

8. Victora CG, César JA. Saúde materno-infantil no Brasil. Morbimortalidade e possíveis intervenções. In: Rouquayrol MZ, Almeida-Filho N. Epidemiologia e saúde. 6ạ Ed. São Paulo: Editora Médico e Científica; 2003.

9. Bryce J, Victora CG, Habicht JP, Vaughan JP, Black RE. The multi-country evaluation of the integrated management of childhood illness strategy: lessons for the evaluation of public health interventions. Am J Public Health 2004; 94:406-15.

10. Lambrechts T, Bryce J, Mgalula L, Rowe A, Schellenberg J, El Arifeen S. Health facility surveys: plan for analysis. Geneva: World Health Organization; 2001.

11. Shah D, Sachdev HP. Evaluation of the WHO/ UNICEF algorithm for integrated management of childhood illness between the age of two months to five years. Indian Pediatr 1999; 36:767-77.

12. Armstrong-Schellenberg J, Bryce J, Savigny D, Lambrechts T, Mbuya C, Mgalula L, et al. The effect of Integrated Management of Childhood Illness on observed quality of care of under-fives in rural Tanzania. Health Policy Plan 2004; 19:1-10.

13. Kolstad, PR, Burnham G, Kalter HD, Kenya-Mugisha N, Black RE. The integrated management of childhood illness in western Uganda. Bull World Health Organ 1997; 75 Suppl 1:77-85.

14. Victora CG, Olinto MTA, Nobre LC, Barros FC. The recent fall in diarrhoea mortality in Northeastern Brazil: did ORT play a role? Health Policy Plan 1996; 11:132-41.

15. Huicho L, Dávila M, Campos M, Drasbek C, Bryce J, Victora CJ. Scaling up IMCI to the national level: achievements and challenges in Peru. Health Policy Plan; in press.

Submitted on $21 / \mathrm{Jan} / 2004$ Approved on 18/Mai/2004 